\title{
Management of phyllodes tumour of breast: 5 year experience at Madina Teaching Hospital, Faisalabad.
}

1. FRCS, FCPS, MRCS Associate Professor Surgery Madina Teaching Hospital, Faisalabad.

2. MBBS, FCPS

Senior Registrar Surgery Madina Teaching Hospital and University Medical and Dental College Faisalabad.

3. MBBS, FCPS

Assistant Professor Surgery Madina Teaching Hospital and University Medical and Dental College Faisalabad.

4. MBBS, FCPS

Professor Surgery Madina Teaching Hospital and University Medical and Dental College Faisalabad.

Correspondence Address: Dr. Saira Saleem

Department of Surgery

Madina Teaching Hospital, Faisalabad.

Article received on:

$14 / 07 / 2020$

Accepted for publication: $15 / 10 / 2020$

\begin{abstract}
Saira Saleem ${ }^{1}$, Aysha Rehman², Farhan Javed ${ }^{3}$, Irshad Ahmad ${ }^{4}$
\end{abstract}
\begin{abstract}
Objectives: To determine the oncological outcome of different types of phyllodes tumour (PT) and to analyze the impact of radiotherapy on outcome. Study Design: Experimental study. Setting: Madina Teaching Hospital, Faisalabad, Pakistan. Period: April 2015 to April 2020. Material \& Methods: Female patients diagnosed as phyllodes tumour of breast were included and classified into benign, borderline and malignant PT according to WHO criteria. Borderline and malignant PT were further divided into 2 groups; Group A (Surgery alone) and Group B (Surgery + Radiotherapy). Oncological outcome based on local recurrence, distant metastasis and overall survival rate among different types of phyllodes tumour and those patients who received or not received radiotherapy was assessed. Results: In 5 years, 29 patients of phyllodes tumour were studied. 15 (51.7\%) patients had benign, 8 (27.6\%) malignant and $6(20.7 \%)$ borderline tumour. Mean age of our patients was 39.5 years (range: $25-55$ years). The disease free survival rate was $82.8 \%$ (100\% for benign, $83.4 \%$ for borderline and $50 \%$ for malignant PT). Malignant histotype and tumour size $>6 \mathrm{~cm}$ were significantly associated with recurrence $(p<0.05)$. In Group A, 4 patients developed local recurrence and 2 of them developed distant metastasis; while in group B only 1 patients developed local recurrence $(p=0.2, O R=0.147)$. Overall survival rate was $93.1 \%$. It was $100 \%$ for radiotherapy group compared to $88 \%$ for non irradiated patients. Conclusion: Malignant phyllodes tumour and large tumour size is associated with worse prognosis. Post operative radiotherapy is associated with improved local recurrence, distant metastasis and overall survival.
\end{abstract}

Key words: $\quad$ Local Recurrence, Metastasis, Phyllodes Tumour, Post operative Radiotherapy.

Article Citation: Saleem S, Rehman A, Javed F, Ahmad I. Management of phyllodes tumour of breast: 5 year experience at Madina Teaching Hospital, Faisalabad. Professional Med J 2021; 28(1):9-15.

https://doi.org/10.29309/TPMJ/2021.28.01.5576

\section{INTRODUCTION}

Phyllodes tumours (PT) of the breast are large and rapidly growing fibroepithelial tumours of the breast that account for less than $1 \%$ of all the breast tumours. These tumours remain as poorly understood tumours of the breast as randomized controlled trials are lacking to establish a standard management protocol due to their rarity. ${ }^{1,2}$ These tumours usually occur in females in the third and fourth decades. ${ }^{3}$

PT shows a diverse biologic behaviour. In their least aggressive form, they behave similarly to benign fibroadenoma, although, they grow rapidly and show a propensity for local recurrence. Presence of epithelial component differentiates it from stromal sarcomas. ${ }^{4}$ Virchow (1867) characterized this tumor as of limited malignant potential but capable of metastasizing. Involvement of Axillary lymph nodes is rare, but blood borne spread is seen into lungs, pleura, bone, and liver. ${ }^{5}$ These tumours are classified into benign, borderline and malignant subtypes by The World Health Organization (WHO), based on the frequency of mitosis, margins invasion, stromal overgrowth, degree of atypia of stromal cell and appearance of margins. ${ }^{6}$

The main treatment option of phyllodes tumor remains surgery. Breast conservation is preferred whenever possible. Management Guidelines of National Comprehensive Cancer Network (NCCN) for the phyllodes tumors recommend wide tumour excision with a margin of $\geq 1 \mathrm{~cm}^{7}$ However, even taking a wide surgical margin, local recurrence rate remains high and is reported 
to be as high as 21-36\% for borderline and malignant tumors. Furthermore, a more malignant phenotype has been seen in recurrent phyllodes tumors and a metastasis in up to $25 \%$ of patients have been estimated in such cases. ${ }^{1}$ Mastectomy is indicated if tumour is large and wide margins cannot be achieved by breast conservation. ${ }^{2}$ As the axillary lymph nodes are rarely involved in $\mathrm{PT}$, routine axillary lymph node dissection is not recommended. ${ }^{7,8}$ After surgery, because of the strong potential of tumor recurrence, patients have been treated with adjuvant radiotherapy. Research has shown variable results of impact of radiotherapy on disease recurrence. ${ }^{1,9,10}$

Currently, the impact of adjuvant radiotherapy on a patient's overall survival or disease free survival outcome for phyllodes tumours remains controversial. $^{9}$ In this article we evaluated the oncological outcome in different types of phyllodes tumour and prognostic impact of adjuvant radiotherapy over a 5-year period.

\section{MATERIAL \& METHODS}

An experimental study was conducted from March 2015 to March 2020. Female patients with phyllodes tumour of breast were included in the study. Patients with metastatic tumour and those with severe systemic diseases were excluded from the study. This was a non probability purposive sampling. Female patients with suspected phyllodes tumour were evaluated in Breast Clinic of Madina Teaching Hospital and were subjected to triple assessment. Most of the patients were diagnosed phyllodes tumour on core needle biopsy as the role of FNAC to diagnose phyllodes tumor remains controversial and an overall accuracy of around $63 \%$ is seen with FNAC. Core needle biopsy gives extra architectural information provided by histology and its sensitivity is reported to be around $99 \% .{ }^{11}$ Some of our patients with diagnostic confusion underwent incisional biopsy. Those with malignant phyllodes underwent metastatic workup. Decision for breast conservation surgery or mastectomy was based on size of tumour and tumour to breast size ratio. Breast conservation surgery was done by wide local excision taking $>1 \mathrm{~cm}$ gross tumour free margin. In patients with large tumour to breast ratio or those with a huge mass involving $>70 \%$ of breast volume, mastectomy was performed. Axillary lymph nodes dissection was not performed in either method. Cases with close margin on histopathology $(<1 \mathrm{~mm})$ were supposed to undergo a revision surgery.

Cases of benign phyllodes tumour (15 patients) underwent surgical treatment only, however those with borderline and malignant phyllodes tumour (14 patients) were divided into 2 equal groups with 7 patients in each group; Group A (Surgery alone) and Group B (Surgery + Radiotherapy). Following wound healing, half of the patients were referred to regional oncology centre for radiotherapy. External beam radiotherapy (EBRT) was given to the patients in a dose of 50 Gray.

Follow up was done every 3 months in first year, 6 monthly in second year and annually thereafter. At each follow up visit, clinical assessment and ultrasonography was performed to detect local recurrence or distant metastasis. For recurrent malignant cases, mastectomy was performed. However, in recurrent borderline case, wide local excision was performed, followed by radiotherapy. Metastases was managed in accordance with principles of soft tissue sarcoma.

The outcome parameters included the local recurrence rate, distant metastasis (DM), disease free and overall survival rates. Local recurrence rate refers to the proportion of the patients who develop local recurrence after surgery. Overall survival rate refers to proportion of patients who survive from date of surgery till the end of study.

This study was approved by the ethical Review committee of hospital. Patients were well informed about the surgical procedure and a signed informed consent was taken prior to surgery.

\section{Statistical Analysis}

Categorical data are presented as frequency and percentage. Fisher's exact test was used for comparison of the two groups of categorical variables. Continuous data are presented as mean and standard deviation. Clinicopathoogical factors of prognostic significance, like patient age, 
tumour size, histological type, type of surgery and postoperative radiotherapy were evaluated. Kaplan Meier method was used to estimate the overall survival rates for benign, borderline and malignant cases and those who received or not received radiotherapy. Patients without disease recurrence, and those who survived were censored at the end of study. A p value of $<0.05$ was considered significant. Data was analysed on $\mathrm{R}$ statistical software version 4.0.0.

\section{RESULTS}

We found mean age of our patients was 39.5 years (SD 6.95) with a range of 25-55 years. The mean tumor size was $6 \mathrm{~cm}(\mathrm{SD}=2.48)$ with a range of $2.8-14.5 \mathrm{~cm}$. Histologically, 15 patients had benign, 8 patients malignant and 6 borderline phyllodes. Table-I shows clinical features and treatment options in different histological types of phyllodes tumour.

Eleven patients (38\%) were treated with mastectomy and $18(62 \%)$ with breast conservative surgery (BCS). Axillary surgery was not carried out in any patients as no patient had clinical or radiological signs of nodal involvement. Figure-1 a \& b shows a comparison of operative time and hospital stay in BCS and Mastectomy, showing a mean operative time of 50 min and a mean hospitals stay of 3.6 days in BCS as compared to 68.6 min and 6.2 days respectively in MRM group.
Regarding type of surgery and local recurrence (In borderline and malignant cases); $20 \%$ of BCS and $33.3 \%$ of mastectomy cases developed local recurrence. We have seen that malignant histology and larger tumour size were other factors contributing to poor outcome in MRM group. All patients were followed at outpatient department (OPD) every 3 months in first year, every 6 months in second year and then annually for 5 years. Table-II shows predictive factors and their association with local recurrence. Fifty percent of the patients with malignant and borderline phyllodes received postoperative radiotherapy. After a mean follow-up period of 34.6 months (range 3-60 months), 4 patients of group $A$ and 1 patient of group $B$ developed local recurrence $(p=0.2)$. Although $p$ value of 0.2 is not significant (probably due to small sample size), Odds ratio of 0.147 signifies that pts who received radiotherapy have only $14.7 \%$ chances of developing recurrence as compared to 85.3 $\%$ chance in non radiotherapy group. Regarding histological types, 4 malignant PT cases developed local recurrence, 1 borderline case developed recurrence. No benign case developed recurrence. $(p=0.007)$. Out of recurrent cases Two patients with malignant histology developed distant metastasis to lung and both died within a year of recurrence and metastasis.

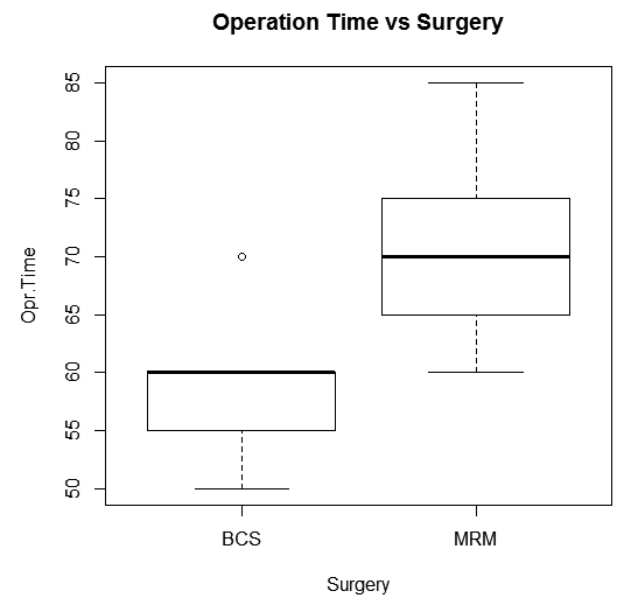

Figure-1a. Operation time vs surgery (BCS/MRM)

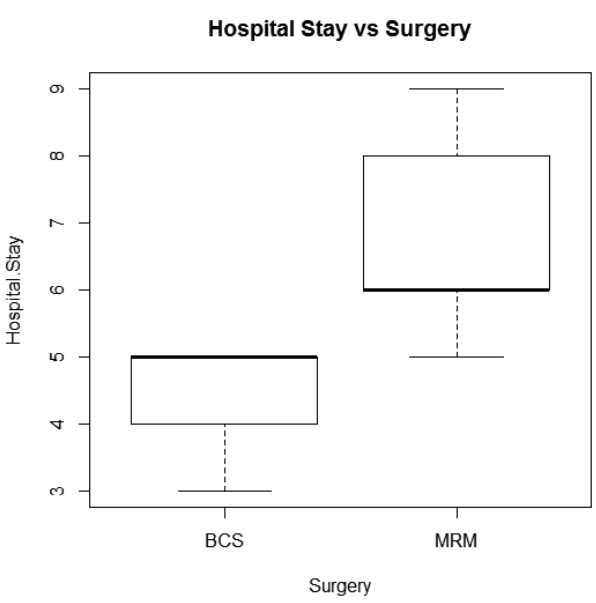

Figure-1b. Hospital Stay vs Surgery (BCS/MRM) 


\begin{tabular}{|c|c|c|c|}
\hline Variables & Benign Phyllodes & Borderline Phyllodes & Malignant Phyllodes \\
\hline $\begin{array}{l}\text { Age } \\
\text { Mean: } 39.5 \\
\text { (Range: } 25-55 \text { ) }\end{array}$ & $\begin{array}{c}36.1 \\
(25-46)\end{array}$ & $\begin{array}{c}39.2 \\
(33-44)\end{array}$ & $\begin{array}{c}46.3 \\
(38-55)\end{array}$ \\
\hline $\begin{array}{l}\text { Clinical size of tumour } \\
\text { Mean: } 6 \mathrm{~cm} \\
\text { (Range: } 2.8-14.5 \text { ) }\end{array}$ & $\begin{array}{c}5 \\
(3.2-9.8)\end{array}$ & $\begin{array}{c}5.4 \\
(2.8-7.2)\end{array}$ & $\begin{array}{c}8.3 \\
(5-14.5)\end{array}$ \\
\hline $\begin{array}{l}\text { Site of tumour }(\%) \\
\text { UOQ }(41.4 \%) \\
\text { LOQ }(13.8 \%) \\
\text { UIQ }(6.9 \%) \\
\text { LIQ (10.3\%) } \\
\text { Central }(13.8 \%) \\
>1 \text { Quadrant }(13.8 \%)\end{array}$ & $\begin{array}{l}7 \\
3 \\
1 \\
2 \\
1 \\
1\end{array}$ & $\begin{array}{l}3 \\
0 \\
1 \\
0 \\
2 \\
1\end{array}$ & $\begin{array}{l}2 \\
1 \\
0 \\
1 \\
1 \\
2\end{array}$ \\
\hline $\begin{array}{l}\text { Type of Surgery: } \\
\text { Breast conservation (BCS) } \\
\text { Mastectomy (MRM) }\end{array}$ & $\begin{array}{l}13(86.6 \%) \\
2(13.3 \%)\end{array}$ & $\begin{array}{l}3(50 \%) \\
3(50 \%)\end{array}$ & $\begin{array}{l}2(25 \%) \\
6(75 \%)\end{array}$ \\
\hline $\begin{array}{ll}\text { Post op Radiotherapy } & \text { Yes } \\
& \text { No }\end{array}$ & $\begin{array}{c}0 \\
15\end{array}$ & $\begin{array}{l}3 \\
3\end{array}$ & $\begin{array}{l}4 \\
4\end{array}$ \\
\hline
\end{tabular}

Table-I. Clinical features and treatment of different histological types of phyllodes tumour

\begin{tabular}{|c|c|c|c|c|}
\hline Features & Total Cases (\%) & LR cases (\%) & P-Value & OR \\
\hline $\begin{array}{l}\text { Age (years) } \\
<40 \\
>40\end{array}$ & $\begin{array}{l}15 \\
14\end{array}$ & $\begin{array}{l}1 \\
4\end{array}$ & 0.17 & 0.19 \\
\hline $\begin{array}{l}\text { Tumour size } \\
<6 \\
>6(\mathrm{~cm})\end{array}$ & $\begin{array}{l}18 \\
11\end{array}$ & $\begin{array}{l}1 \\
4\end{array}$ & 0.036 & 0.09 \\
\hline $\begin{array}{l}\text { Histotype: } \\
\text { Benign } \\
\text { Borderline } \\
\text { Malignant }\end{array}$ & $\begin{array}{l}15 \\
6 \\
8\end{array}$ & $\begin{array}{l}0 \\
1 \\
4\end{array}$ & 0.007 & Infinity \\
\hline $\begin{array}{l}\text { Type of Surgery } \\
\text { BCS } \\
\text { MRM }\end{array}$ & $\begin{array}{l}18 \\
11\end{array}$ & $\begin{array}{l}1 \\
4\end{array}$ & 0.053 & 8.9 \\
\hline $\begin{array}{l}\text { Radiotherapy } \\
\text { Yes } \\
\text { No }\end{array}$ & $\begin{array}{l}7 \\
7\end{array}$ & $\begin{array}{l}1 \\
4\end{array}$ & 0.2 & 0.147 \\
\hline
\end{tabular}

The distant metastasis and overall survival rate was $93.1 \%$. Kaplein Meire curve (Figure-2) shows survival benefit of radiotherapy. Survival was $100 \%$ for irradiated patients compared to $88 \%$ for non irradiated patients.

We found that size of the tumour, malignant histology and no use of radiotherapy after surgery to be highest risk factors for tumour recurrence, distant metastasis and overall survival.

\section{DISCUSSION}

Phyllodes tumours are rare tumours of breast that exhibit a blend of epithelial component and connective tissue stroma, unlike more common breast cancers that are epithelial in origin. ${ }^{12}$ Most of the tumors arise in women between 35 and 55 years of age, about 20 years later than fibroadenoma. ${ }^{4}$ In our study mean age of the patients was 39.5 years that was similar to other loco regional studies. ${ }^{10,13-15}$ 


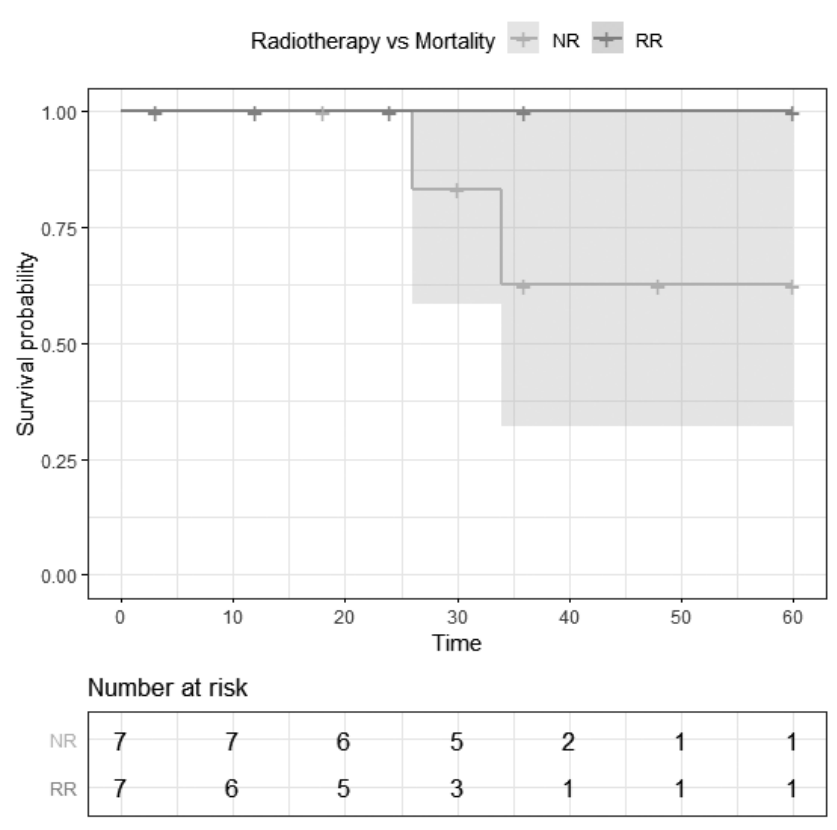

Figure-2. Effect of radiotherapy on 5 year survival of patients with phyllodes tumour.

Note: $\mathrm{NR}=$ No radiotherapy. $\mathrm{RR}=$ Received radiotherapy.

We found 15 cases of benign, 6 borderline and 8 malignant phyllodes that is similar to a pathological study conducted at Mayo Hospital, Lahore. ${ }^{16}$

PT vary in their size with a median size of $4-7 \mathrm{~cm}^{10}$ and tumours sizes of up to $40 \mathrm{~cm}$ has been reported in literature. 5,12 The mean size of phyllodes tumors in our study was $6 \mathrm{~cm}$. In our study larger tumour size ( $>6 \mathrm{~cm}$ ) was commonly related to malignant histology $(75 \%)$, similar to the observation of Ditsatham. ${ }^{17}$

A good diagnostic work up and surgical planning is needed to avoid chances of repeated surgery. Treatment can be either mastectomy or BCS if histologically tumour free margins are ensured. ${ }^{4}$ BCS with wide tumour margins is considered a preferred treatment provided a good cosmetic and oncologic outcome is feasible. ${ }^{18,19}$ A $1-\mathrm{cm}$ margin is considered to be an adequate resection margin and different national and international series report an improved local recurrence and disease-free survival rate with a negative surgical margin. ${ }^{12,13}$ We performed BCS (taking $1 \mathrm{~cm}$ surgical margin) in 18 cases, of which 12 were benign, 3 borderlines and 2 malignant cases. We did not observe any case of tumour recurrence in benign cases. This was similar to the observation of Ren $J$ and colleagues who described no recurrence in benign tumours over a period of 8 years using wide local excision. ${ }^{20}$ In our study mean operative time in BCS was 50 min and mean hospitals stay was 3.7 days. This was shorter than mastectomy. (Figure-2 a,b). Similar observations were reported by Ren $\mathrm{J}$ and colleagues. ${ }^{20}$

In most of the malignant cases and especially those with large tumour size, mastectomy was performed. Mastectomy rate for the malignant phyllodes tumours in this study was $75 \%$. It was reported $81 \%$ by Demian from Egypt owing to larger size of tumor and a high positive margin rate. ${ }^{10}$ It was also observed that most of the cases of mastectomy were performed in older patients and larger tumour size, as compared to BCS. This was similar to the observation of Adesoye T, et al. ${ }^{7}$

To date, a mean local recurrence rate of about 15 $\%$ is reported in most series with a range of $10 \%$ to $40 \% .^{4}$ In our study 5 cases $(17.2 \%)$ developed local recurrence, 4 of which were malignant and one borderline case. Cases became recurrent at mean period of 22 months with a range of 16 to 30 months. Similarly, Tan EY and colleagues reported local recurrence at a median period of 22 months. ${ }^{21}$ We found significant association of factors like size of the tumour, malignant histology and no use of radiotherapy with tumour recurrence (Table-III). Similarly, a study by Ditsatham and colleagues showed tumour size, malignant histology and patient age to be associated with local recurrence. ${ }^{17}$

Limited research is available about the role and effectiveness of adjuvant radiotherapy in reducing recurrences. ${ }^{2,9}$ In our study radiotherapy group developed less recurrence with an odds ratio of 14.7 as compared to 85.3 of non radiotherapy however a $p$ value of 0.2 was observed due to small sample size. Similar results were described by Pandey et al. ${ }^{22}$ In our study $25 \%$ of malignant phyllodes tumour developed distant metastasis, both cases to lungs within a year of local recurrence. Literature also shows most common 
site for distant metastasis to be lungs. ${ }^{4,10,23}$ Mishra and colleagues reported that $25 \%$ of patients with histologically malignant tumors develop distant metastasis, most common site observed for the distant metastases was lungs (66\%) followed by bones (28\%) and brain (9\%). ${ }^{4}$ Similarly, Khosravi $S$ described $22 \%$ of malignant tumors giving rise to haematogenous metastases. ${ }^{24}$ Ramakant $P$ from India reports a poor prognosis of metastatic phyllodes tumors with very few patients surviving more than a year after metastasis. ${ }^{25}$ Both of our cases who developed distant metastasis also died within a year of metastasis.

Figure-2 shows Kaplein Miere curve of impact of radiotherapy on survival. The overall survival rate was $93.1 \%$. It was $100 \%$ for irradiated patients (Group B) compared to $88 \%$ for non irradiated patients. These results were similar to the study of Demian from Egypt. ${ }^{10}$

Small sample size, due to rarity of tumour was a limitation of this study. A multicentric study needs to be conducted to define the role of radiotherapy in preventing recurrence and improvement in overall survival of phyllodes tumour, on a larger scale.

\section{CONCLUSION}

Phyllodes tumour of breast has a propensity of local recurrence and distant metastasis. Malignant phyllodes tumour and large tumour size is associated with worse prognosis. Postoperative radiotherapy improves local recurrence, distant metastasis and overall survival rate.

\section{Copyright $\subseteq 15$ Oct, 2020.}

\section{REFERENCES}

1. Chao X, Chen K, Zeng J, Bi Z, Guo M, Chen Y, et al. Adjuvant radiotherapy and chemotherapy for patients with breast phyllodes tumors: A systematic review and meta-analysis. BMC Cancer 2019; 19: 372. https://doi.org/10.1186/s12885-019-5585-5.

2. Varghese SS, Sasidharan B, Manipadam MT, Paul MJ and Backianathan S. Radiotherapy in Phyllodes tumour. J Clin Diagn Res 2017; 11(1): XC 01-XC 03. doi: 10.7860/JCDR/2017/24591.9167.
3. Testori, A, Meroni, S, Errico, V. Huge malignant phyllodes breast tumor: A real entity in a new era of early breast cancer. World J Surg Onc 2015; 13:81. https://doi.org/10.1186/s12957-015-0508-7.

4. Yogi V, Singh OP, Malviya A, Ghori HU. Effect of postoperative time for adjuvant radiotherapy in malignant phyllodes tumor: An institutional experience. J Can Res Ther 2018; 14: 1054-8.

5. Mishra SP, Tiwary SK, Mishra M, Khanna AK. Phyllodes tumour of breast: A review article. ISRN Surg. 2013; 2013: doi: 10.1155/2013/361469.

6. Nguyen NT, Maciolek LM, Qu S, Sadruddin S, Nguyen QD. Malignant Phyllodes Tumor of the Breast in a 26-year-old Woman. Cureus. 2020 Jan;12(1). doi:10.7759/cureus.6590.

7. Adesoye T, Neuman HB, Wilke LG, Schumacher JR, Steiman J, Greenberg CC. Current trends in the management of phyllodes tumors of the breast. Ann Surg Oncol. 2016; 23 (10): 3199-3205. doi:10.1245/ s10434-016-5314-0.

8. Chen W-H, Cheng S-P, Tzen C-Y, Yang T-L, Jeng K-S, Liu $\mathrm{C}-\mathrm{L}$, et al. Surgical treatment of phyllodes tumours of the breast: Retrospective review of 172 cases. J Surg Oncol. 2005; 91(3):185-94.

9. Constance, Joseph. "Radiotherapy and chemotherapy for phyllodes tumors". News-Medical. https:// www.news-medical.net/health/Radiotherapy-andChemotherapy-for-Phyllodes-Tumors.aspx. (accessed April 05, 2020).

10. Demian GA, Fayaz S, Eissa HE, Nazmy N, Samir S, George T, et al. Phyllodes tumour of the breast: Analysis of 35 cases from a single institution. J Egypt Natl Canc Inst 2016; 28(4): 243-48. https://doi. org/10.1016/j.jnci.2016.06.004.

11. Komenaka IK, El-Tamer M, Pile-Spellman E, Hibshoosh $\mathrm{H}$. Core needle biopsy as a diagnostic tool to differentiate phyllodes tumor from fibroadenoma. Archives of Surgery. 2003; 138(9):987-990. [PubMed] [Google Scholar].

12. Harris JR, Lippman ME, Osborne CK, Morrow M. Diseases of the Breast. Lippincott Williams \& Wilkins; 2012 Mar 28.

13. Bhargav PR, Mishra A, Agarwal G, et al. Phyllodes tumour of the breast: Clinicopathological analysis of recurrent vs. non-recurrent cases. Asian J Surg 2009; 32:224-8.

14. Badar F, Mahmoood S, Syed AA, Siddiqui N. Malignant phyllodes tumour of the breast. J Ayub Med Coll 2012; 24(3): 47-49. 
15. Sawalhi S, Al-Shattib M. Phyllodes tumor of the breast: A retrospective study of the impact of histopathological factors in local recurrence and distant metastasis. Ann Saudi Med 2013; 33(2): 162168.

16. Arshad M, Niazi S. Breast phyllodes tumour: A 6-year retrospective series analysis at Mayo hospital/ King Edward Medical University, Lahore Pakistan. J Sharif Med \& Dental College Lahore Pakistan 2019; 5 (02): 6570.

17. Ditsatham C, Chongruksut W. Phyllodes tumor of the breast: Diagnosis, management and outcome during a 10-year experience Cancer Manage Res. 2019; 11 : 7805-7811. Published online 2019 Aug 19. doi: 10.2147/ CMAR.S215039).

18. National Comprehensive Cancer Network. Phyllodes Tumor (Version 1.2016) [Accessed January 25, 2016]; http://www.nccn.org/professionals/physician_gls/pdf/ breast.pdf. [Google Scholar].

19. Macdonald OK, Lee CM, Tward JD, Chappel CD, Gaffney DK. Malignant phyllodes tumor of the female breast: Association of primary therapy with cause-specific survival from the Surveillance, Epidemiology, and End Results (SEER) program. Cancer. 2006; 107(9):2127-2133.
20. Ren J, Jin L, Leng B, Hu R and Jiang G. Surgical excision and oncoplastic breast surgery in 32 patients with benign phyllodes tumors. World J Surg Oncol 2018; 16: 153. https://doi.org/10.1186/s12957018-1453-z.

21. Tan EY, Tan PH, Yong WS, et al. Recurrent phyllodes tumours of the breast: pathological features and clinical implications [published correction appears in ANZ J Surg. 2006 Oct; 76(10):956. Hoon, Tan Puay [corrected to Tan, Puay Hoon]; Hui, Ho G [corrected

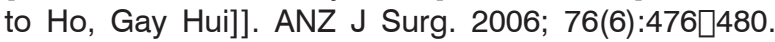
doi:10.1111/j.1445-2197.2006.03754.x.

22. Pandey M, Mathew A, Abraham EK, et al. Primary sarcoma of the breast. J Surg Oncol 2004; 87:121-5.

23. Gülben, K., Öndeş, B. \& Berberoğlu, U. Factors affecting local recurrence for phyllodes tumors of the breast: A retrospective analysis of 89 patients in a single center. Indian J Surg 2019. DOI: 10.1007/ s12262-019-02031-x.

24. Khosravi SP. Management of non metastatic phyllodes tumors of the breast: Review of the literature. Surg Oncol 2011; 20(4); 143-8. doi: 10.1016/j. suronc.2011.04.007. Epub 2011 May 24.

25. Ramakant P, Selvamani, Therese MM, Paul MJ. Metastatic malignant phyllodes tumor of the breast: An aggressive disease-analysis of 7 cases. Indian $\mathrm{J}$ Surg Oncol. 2015; 6(4):363-369. doi:10.1007/s13193015-0397-9.

\begin{tabular}{|c|c|c|c|}
\hline \multicolumn{4}{|c|}{ AUTHORSHIP AND CONTRIBUTION DECLARATION } \\
\hline Sr. \# & Author(s) Full Name & Contribution to the paper & Author(s) Signature \\
\hline 1 & Saira Saleem & $\begin{array}{l}\text { Corresponding author, Writing of } \\
\text { manuscript. }\end{array}$ & \\
\hline 3 & Farhan Javed & Proof reading. & \\
\hline 4 & Irshad Ahmad & $\begin{array}{l}\text { Review of literature \& Proof } \\
\text { reading. }\end{array}$ & \\
\hline
\end{tabular}

